\title{
Study on Scientific Research and Innovation Oriented Cultivation Model of Postgraduate
}

\author{
Zhiyu Zhou * \\ School of Information Science and Technology, \\ Zhejiang Sci-Tech University, \\ Hangzhou 310018, China \\ zhouzhiyu1993@163.com
}

\author{
Haiyan Wang \\ Department of Safety Protection, \\ Zhejiang Police Vocational Academy, \\ Hangzhou 310018, China \\ 1049788818@qq.com
}

\begin{abstract}
The cultivation of postgraduates' innovative aware ness, innovative spirit, and innovative ability is the need to adapt to society's senior talents with innovative ability and thinking. In the study on scientific research and innovation oriented cultivation model of academic postgraduates, the ability in teaching and research of instructor will be steadily improved through continuously optimizing knowledge structure of instructor. By participating in the instructor's scientific research project, academic postgraduates should be encouraged to publish SCI papers. Through the combination of theoretical study and corporate practice, the ability to find and solve problems is cultivated; so as to actualize cultivation of innovative ability combined practical teaching with research training in postgraduates.
\end{abstract}

Keywords-innovative ability; cultivation model of postgraduates; scientific research training; innovative spirit

\section{INTRODUCTION}

The mission to postgraduate education is to cultivate advanced information talents with innovative spirit and practical ability. In the information age, only people with innovative awareness, innovative spirit, and innovative ability can make more achievements. The cultivation of their innovation is the key to the improvement of the quality in higher information education, and it is also the basic orientation of the practical teaching reform in university information specialty. Constantly create a creative atmosphere for postgraduate students, carry out innovative education, and guide innovative practices, so that postgraduates will consciously have innovative wish and creative desire to actively transform the status of objective things in movement. Therefore, the study on the cultivation of postgraduates' innovative ability unites practical teaching and research training is particularly meaningful. To make the talents cultivated by colleges and universities better cultivate their innovative abilities, many scholars have studied the training of postgraduates' innovative abilities from different perspectives. In the reform of practice teaching in cultivation of innovative ability, Dai[1] put forward the close combination of reform about practice teaching in colleges and universities, the construction of practical teaching instructor team, the optimization of practical teaching content system, the improvement of practical teaching platform conditions, the reorganization of practical teaching modules project, the improvement of practical teaching management mechanism, the reform of practical teaching evaluation methods, and other supporting measures to explore the systemic teaching model of the practical model in tutorial system. In the research and practice of postgraduate education and teaching reform research and practice project goal management, process cultivation, humanities education, and work of party and communist, the "four in one" education and cultivation model, Lv[2] proposed the scientific research and innovation of postgraduates for Ph.D degree students in science and engineering, their ability cultivation is a continuous and uninterrupted process, and the ability of scientific research and innovation runs through the entire process of student learning and life at school. Simultaneously, this cultivation process should form a consensus under the efforts of all parties, only in this way can we cultivate high quality graduate for Ph.D. degree. Sun [3] proposed a new teaching model of "practice + innovation training” for existing teaching model of mechanical engineering, and improved the cultivation of mechanical engineering postgraduates in practical and innovative interaction and teaching and learning atmosphere by establishing a management coordination mechanism between school-enterprise joint coordination center and school. In the research on the status of interdisciplinary talents cultivation and their institutional mechanisms in research universities, $\mathrm{Xu}$ [4] proposed the use of problem solving-based learning approaches for interdisciplinary courses and teaching, and the idea of creating interdisciplinary research institutions as core is changed to interdisciplinary postgraduates who have interdisciplinary cooperation projects for the concept of linking up the project and the mentor team, and adopt multi-variable and flexible evaluation methods for interdisciplinary graduate student guidance. $\mathrm{Xu}[5]$ put forward the school-enterprise cooperation as the basis to strengthen the deep integration of theory and practice, highlight the instructor's team guidance, strengthen the practical exercise of scientific research projects, pay attention to the coordination of the practice platform, and improve the overall quality of graduate students in all directions, simultaneously, strengthened quality assurance system and gradually established characteristic postgraduates cultivation model in the field of postgraduates cultivation with the principle of "giving play to team strengths, strengthening coordination and cooperation, highlighting engineering practices, and serving the oceanographic examinations”. Xu [6] proposed that postgraduates should participate in major scientific research projects, stimulate their interest, and enhance their sense of innovation. The instructor team can 
cultivate the teamwork spirit of postgraduates; increase academic activities and academic exchange activities, and study academic frontier topics so that postgraduates have a good innovation, practical and teamwork awareness. For the specific issues of the backward content of postgraduates in the cultivation of innovative practical ability and the weak teaching in innovative practice, Chen[7] proposed to build a new innovation practice platform that facilitates the cultivation of postgraduates' innovation and encourages postgraduates to actively participate in innovative practice projects. In response to the current status of domestic postgraduates cultivation, Jia[8] proposed a set of innovative postgraduates training programs based on the principle of teaching students according to their aptitude, and in the context of the unified management of laboratories, which aims to export specialized talents with advanced scientific research capabilities to the country, and who has high quality.

\section{TRAINING MODEL AND APPROACH}

At present, the cultivation model of major universities include "curriculum model", "apprenticeship model" and "course + papers combination model". Inspired by the above literature, in the process of presiding over the key research project of postgraduates education reform " in the study on scientific research and innovation oriented cultivation model of academic postgraduates", the research on the cultivation of postgraduates' innovative ability combined with practical teaching and scientific research training was proposed. This study aims to steadily improve the teaching and research level of instructors by continuously optimizing the knowledge structure of teachers. By allowing postgraduates to participate in the scientific research projects of instructors, academic postgraduates are encouraged to actively publish SCI papers. Through the combination of theoretical learning and corporate practice, the ability of postgraduates to find and solve problems is improved.

\section{A. Optimize the Knowledge Structure of Teacher Team and Improve the Teaching and Research Level of Instructors}

A high-quality teaching team can provide students with powerful scientific research guidance. In cultivation of informational postgraduates, the guidance of teachers' knowledge structure and academic interest has a subtle influence and demonstration effect on informational postgraduates. The author studied a doctoral degree in mechanical engineering of Zhejiang Sci-Tech University, during who arrange a key postgraduates education reform project "on the study on scientific research and innovation oriented cultivation model of academic postgraduates", although the title of the Ph.D "study on target tracking and motion control of mobile robot", "study on manipulator's target identification and motion planning technology" were all rejected by the School of Mechanical Engineering for failing to meet the requirements of mechanical engineering. However, the author insisted on the study about automation of robotic manipulators. Ultimately, kinematics and dynamics were the analytical tools, and the manipulator's visual servo control technology has conducted in-depth research and adopted the "Research on the manipulator's visual servo control technology" to pass the defense of Ph.D. In the process of studying for a Ph.D degree, the author's knowledge structure was optimized and the level of teaching and research was improved. At the same time, the perseverance of the mental and emotional state that this type of research activity displayed has also infected the postgraduates who have been supervised, which has significantly stimulated the intrinsic motivation of postgraduates for scientific research, and which not only increase the confidence of graduate students in scientific research, but also help them adjust the mentality of the failure in scientific research process.

\section{B. Maintaining Participate in Research Projects of Instructor and Encourage Academic Postgraduates to Publish SCI \\ Papers}

In the course of guiding postgraduates, the author successively chaired the Zhejiang Provincial Natural Science Fund Project "Target Tracking and Grasp of Manipulators Based on Extreme Learning Machine and Visual Servoing" (No: LY18F030018), and "Research on Key Technologies of Robot Autonomous Navigation Based on Stereo Vision in Natural Environment" (No: LY13F030013), and "Target Visual Analysis Based on Grey Modeling" (No. Y1090256), which have created the conditions for postgraduates to participate in instructors' research projects.

To publish SCI papers on robot target tracking, it is necessary to read a large number of outstanding papers about robot target tracking, to understand the latest and most cuttingedge scientific research trends in robot target tracking, and to select novel topics with research value on these basses, "Target Tracking and Grabbing of Robot Manipulators Based on Extreme Learning Machine and Visual Servoing" was funded by the Natural Science Foundation of Zhejiang Province. The analysis of the results and explanation of problems are started from a new perspective. For example, the paper "Multiple instance learning tracking based on fisher linear discriminant with incorporated priors" was published in "International Journal of Advanced Robotic Systems" used significance test of statistical theory to analysis the results. Taking advantage of the cutting-edge and innovative nature of SCI papers to cultivate postgraduates' innovation sense and ability to innovate is a practical and feasible way to improve postgraduates' innovative capabilities. In practice, we actively cultivate graduate students to participate in scientific research projects and encourage academic graduate students to publish SCI papers. The conclusion of the postgraduate students' degree dissertation fostering fund project stipulates that science and engineering academic postgraduate master's thesis should publish (includes accept) 1 SCI or EI journal paper, and the doctoral dissertation must publish the SCI paper. In the training of postgraduates' innovation guided by SCI thesis, during the implementation of this education reform project, the authors jointly published six SCI papers with postgraduates. The postgraduates trained are highly welcomed by their peers for their powerful ability in scientific and technological innovation, two master students who graduated have received excellent master's thesis this year.

The review specialist of SCI journals almost has a high level, the review process is extremely rigorous, and the published papers have great influence, so the international 
scientific and technological community are took these journals seriously. Therefore, in process of guiding graduate students to publish SCI, The instructor must make great efforts to every aspect of paper's thinking, writing and modifying, and the initiation and creativity of postgraduates should be aroused adequately. The scientific and technical papers should be guided in detail. The frame structure of paper should be carefully conceived and the research data should be carefully examined. The verifiability of experimental results and rationality of references are also important. They must be carefully studied. The review result to paper must be thought seriously, and the suggestion of experts should be respected fully. Therefore, in the process of publishing journal articles in SCI to improve the research and innovative ability of postgraduates, it is also necessary for the instructors to make more efforts, so as to truly further develop the vision of graduate students and master key technologies of current research, thereby enhancing innovation awareness and innovation ability of postgraduates.

\section{Through the Combination of Theoretical Study and the Practice of Companies, to Cultivate the Ability of Postgraduates to Find Problems and Solve Problems}

Innovation sense needs to be induced through continuous learning and practice. The cultivation of innovative spirit requires long-term innovation education and innovative practice, and gradually fosters creative emotions such as creative desire and tough will. Innovation thinking is a crystallization of many kinds of thinking development, such as seeking difference, reasoning, imagination, association and divergence, in the process of training innovative thinking, we must adhere to inquiry-based learning strategies, collaborative learning strategies and emotional incentive strategies, and in a long term, innovative education and innovation practice, the spirit of tenacity and truth will be gradually cultivated.

The joint construction of research and development platforms between universities and industry enterprises is an effective way to promote the joint training of postgraduates, and can improve postgraduates' research and innovative capabilities. In the synergy of production and learning, the innovation of graduate students' cultivation concept will be promoted, training mode and training process, and realize the transformation of scientific research achievements into realistic productivity, so as to cultivate top-notch innovative talents and promote the development of interdisciplinary. The development of school-industry alliances has given postgraduates opportunity to take part in the development of major projects or the research and development of new products. Through practicing in the enterprise, postgraduates can actively discover problems and solve problems in real work. After the establishment of the Xinchang Technical Innovation Research Institute of Zhejiang Sci-Tech University, forwardlooking technology research and development around the key technical problems are carried out in Xinchang's industrial development, and help them to overcome technological bottlenecks in the development of enterprises, and enhance the ability to independent innovation of enterprises, what's more, technological reserves are provided for development of enterprises. Zhejiang Sci-Tech University Xinchang Postgraduates Joint Training Base has given us four graduate student recruitment quotas for this year's College of Information Science. In the first year of postgraduates training, the curriculum was completed at school, and then the research and dissertation would be conducted in Xinchang's joint training base. And the dual-tutor system was implemented. The base provided free accommodation, living and working conditions for graduate students, and the Xinchang government provided 10,000 scholarships each year to students, and provides project support and work funding support to teachers. The school-enterprise co-construction platform promotes application of postgraduates' knowledge acquired in schools to practical enterprises, stimulates their interest in exploring the unknown world, and enhances scientific and technological innovation capabilities of them, enhances their innovative qualities, and greatly promotes cultivation of postgraduates' innovative ability.

\section{CONCLUSION}

The cultivation of postgraduates' innovation is a systematic project that requires long-term efforts, and every instructor should constantly explore and be bold in innovation in practice. In the optimization of the knowledge structure of teachers, and continuously improve the research level of instructors, they can also apply for more research projects to provide scientific research to graduate students. Through joint construction of research and development platforms by schools and enterprises, the postgraduates' ability to innovate has been continuously improved in production-study collaboration, and innovative ideas of postgraduates have been established to meet the needs of today's society for innovative talents.

\section{ACKNOWLEDGMENT}

This research was financially supported by the postgraduate research project of education and teaching reform of Zhejiang Sci-Tech University (YJG-Z17003).

\section{REFERENCES}

[1] Dai Nianhong, "Study on tutorial system practice teaching model based on cultivation of innovation ability: a case study of the public service management major of hunan university of science and technology," Theory and Practice of Contemporary Education, vol.10, no.1, pp 57-60, 2018.( In Chinese)

[2] Lv Peng, Liu Xin-lin, Yan Yong-sheng, "Research on scientific research training and ability broadening of science and engineering doctoral students,” Education Teaching Forum, vol.10, pp 1-2, 2017. (In Chinese)

[3] Sun Ying, Cheng Wen-tao, Zhu Wenqiong, et al, "Innovation of training mode of mechanical engineering graduate based on school - enterprise cooperative center,” Education Teaching Forum, vol.16, pp31-33, 2018. ( In Chinese)

[4] Xu Lan, Tao Tao, "Innovation of Training Models in Interdisciplinary Postgraduate Education: Focused on Competence and Identity,” Journal of Xiamen University (Arts \& Social Sciences), vol. 2, pp65-74, 2018. ( In Chinese)

[5] Xu Hong, Yu Hai-bin, Liu Jing-biao, “An Exploration on Cultivation of Innovative Practice Ability of Graduate Students in Marine Engineering,” Journal of Hangzhou Dianzi University (Social Sciences), vol. 14, no.1, pp65-69, 2018. (In Chinese)

[6] Xu Xiao-jin, Weng Lu-mei, Zheng Wan-mei, et al., “A Study of Graduate Innovation Capability Training Model,” Journal of Jimei University, vol. 18, no.4,pp 67-71, 79, 2017. ( In Chinese) 
[7] Chen Jian-jun, Gu Yong-hong, Han Qing-wen, et al., "Cultivation of Innovation Ability of Information Graduates," Education Teaching Forum, vol.17, pp86-87, 2017. ( In Chinese)
[8] Jia He-ming, Zhang Jia-wei, Wu Di, “Exploration on the cultivating path of graduate students' innovative ability,” SCI-TECH Innovation \& Productivity, vol.7, pp 50-52, 2017. ( In Chinese) 